\title{
TAXA DE PREDAÇÃO DE NINHOS ARTIFICIAIS EM UMA ÁREA DE MANEJO FLORESTAL SUSTENTÁVEL NA AMAZÔNIA CENTRAL
}

\author{
Roberta Souza de Moura' \\ Rubia Pereira Ribeiro ${ }^{2}$ \\ José Carlos Rodrigues Soares ${ }^{3}$ \\ Adriene de Oliveira Amaral ${ }^{4}$ \\ Louri Klemann Junior ${ }^{5}$
}

Resumo: A predação de ninhos vem sendo sugerida como uma das causas do declínio de populações de aves, influenciando a estrutura e funcionamento das comunidades. Apesar de diversos estudos terem avaliado fatores relacionados às variações nas taxas de predação de ninhos, poucos verificaram os efeitos do manejo florestal sustentável sobre estas taxas. O presente trabalho teve como objetivo avaliar a influência do manejo florestal sustentável sobre a taxa de predação de ninhos artificiais em uma floresta de terra firme na Amazônia Central. Para isso foram instalados ninhos artificiais em três áreas entre 11/2014 e 06/2015. Dos 240 ninhos montados 72 foram predados, sendo 29 na área não manejada, 24 na Área de Preservação Permanente e 19 na área manejada. Dos 72 ninhos predados 55,56\% foram ninhos de subbosque e 44,44\% ninhos de solo. A menor taxa de predação na área manejada pode estar relacionada às alterações na estrutura da vegetação e ao consequente afugentamento dos predadores.

Palavras-chave: Manejo Florestal Sustentável; Massa de modelar; Amazônia Central.

\footnotetext{
1 Graduando em Engenharia Florestal pela Universidade do Estado do Amazonas (UEA). Brasil. E-mail: robertamourah@gmail.com.

2 Graduando em Engenharia Florestal pela Universidade do Estado do Amazonas (UEA). Brasil. E-mail: rubiamawe@gmail.com.

3 Graduando em Engenharia Florestal pela Universidade do Estado do Amazonas (UEA). Brasil. E-mail: carlosflorestal12@gmail.com.

4 Graduando em Engenharia Florestal pela Universidade do Estado do Amazonas (UEA). Brasil. E-mail: adrienegama@gmail.com.

5 Professor Assistente. Centro de Estudos Superiores de Itacoatiara, Universidade do Estado do Amazonas, Brasil. E-mail: klemannjr@yahoo.com.br.
} 